\title{
Uterine necrosis following B Lynch suture: a rare complication
}

\author{
Susheela Chaudhary ${ }^{1}$, Parul Singh ${ }^{1 *}$, Meenakshi B. ${ }^{1}$, \\ Anjali Gupta', Monika Ramola ${ }^{2}$
}

\begin{abstract}
${ }^{1}$ Department of Obstetrics and Gynecology, Pt BD Sharma PGIMS Rohtak, Haryana, India
${ }^{2}$ Department of Obstetrics and Gynecology, SGRRIMHS, Dehradun, Uttarakhand, India
\end{abstract}

Received: 10 September 2017

Revised: 22 October 2017

Accepted: 08 January 2018

\section{*Correspondence:}

Dr. Parul Singh,

E-mail: drparulsingh01@gmail.com

Copyright: (C) the author(s), publisher and licensee Medip Academy. This is an open-access article distributed under the terms of the Creative Commons Attribution Non-Commercial License, which permits unrestricted non-commercial use, distribution, and reproduction in any medium, provided the original work is properly cited.

\begin{abstract}
The B-Lynch uterine suture brace is a relatively new technique used for treatment of postpartum haemorrhage. These uterine compression sutures have achieved hemostasis while preserving fertility in many women and thus their efficacy and safety have been time tested. Very few complications have been reported following B Lynch suture. These include Asherman's syndrome, hematometra, pyometra, localized areas of uterine necrosis and full-thickness defects in the lower uterine segment or uterine fundus and erosion of uterine wall. Herewith, reporting a case of 23year-old woman who underwent cesarean section for breech presentation. She had atonic PPH for which uterine artery ligation was done along with B-lynch suture. She developed uterine necrosis for which hysterectomy was done. Microsections showed that endometrial cavity was filled with gangrenous slough extending to variable extent in myometrium and cervix.
\end{abstract}

Keywords: Asherman's syndrome, B Lynch suture

\section{INTRODUCTION}

Postpartum haemorrhage (PPH) remains a significant contributor to maternal morbidity and mortality both in developing and developed countries. ${ }^{1,2}$ Uterine atony, or failure of uterus to contract adequately after childbirth, is most common cause of $\mathrm{PPH}{ }^{3}$ Most of the cases of atonic PPH can be managed using uterotonic drugs. However, few patients require surgical intervention for the same. Traditionally, the various modalities included uterus packing, stepwise devascularisation of uterus, internal iliac artery ligation and if these fail, obstetric hysterectomy was done for PPH. Definite surgical management by doing obstetric hysterectomy leads to inability to host any future pregnancy. B-lynch suture and its modifications have added a new modality in the hands of the treating obstetricians before proceeding to obstetric hysterectomy. ${ }^{4}$ To date only few complications of this procedure have been reported. We would like to report a case of B-Lynch suture which caused necrosis of the uterine wall.

\section{CASE REPORT}

A 23-year-old primipara was admitted from casualty with pain abdomen, distension and unable to pass flatus and faeces since last 3 days. She gave h/o lower segment caesarean section 8 days back for primi breech and operative notes revealed atonic PPH managed by conservative surgical method by applying modified Blynch suture along with bilateral uterine artery ligation. On examination, she was pale and febrile to touch. Her vitals were pulse rate 110 per minute and blood pressure 110/60 mm Hg. Abdominal examination revealed distension, tenderness, guarding and rigidity with indurated transverse scar in lower abdomen. Her 
haemoglobin was $8 \mathrm{gm} \%$, total leucocyte count was 20,000 and platelets were adequate. Fever profile was negative for malaria and typhoid. Urine complete examination showed few pus cells. Liver function tests, renal function tests and electrocardiogram was normal.

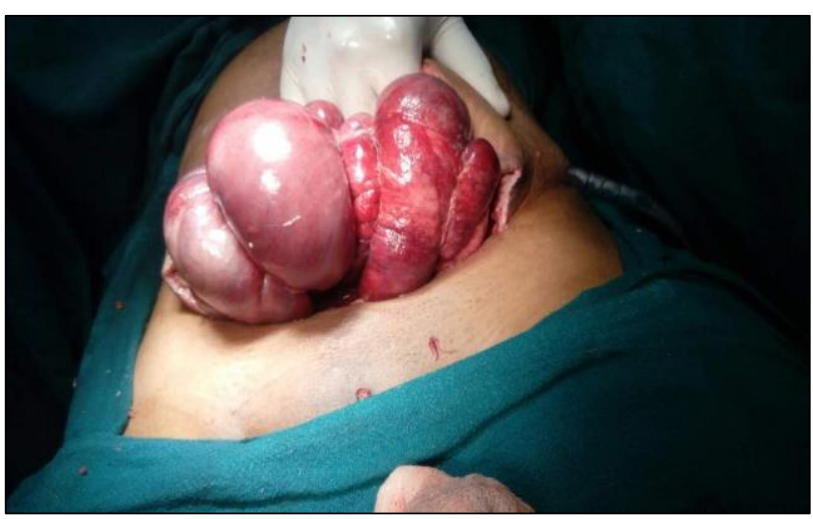

Figure 1: Multiple B Lynch sutures with mild uterine congestion.

Laparotomy was decided suspecting intestinal obstruction by general surgeon. Per operatively, free fluid was $1+$, gut loops were distended, uterus was enlarged to 24 weeks size, mildly congested with multiple compression sutures using delayed absorbable suture material, bilateral tubes and ovaries normal (Figure 1).

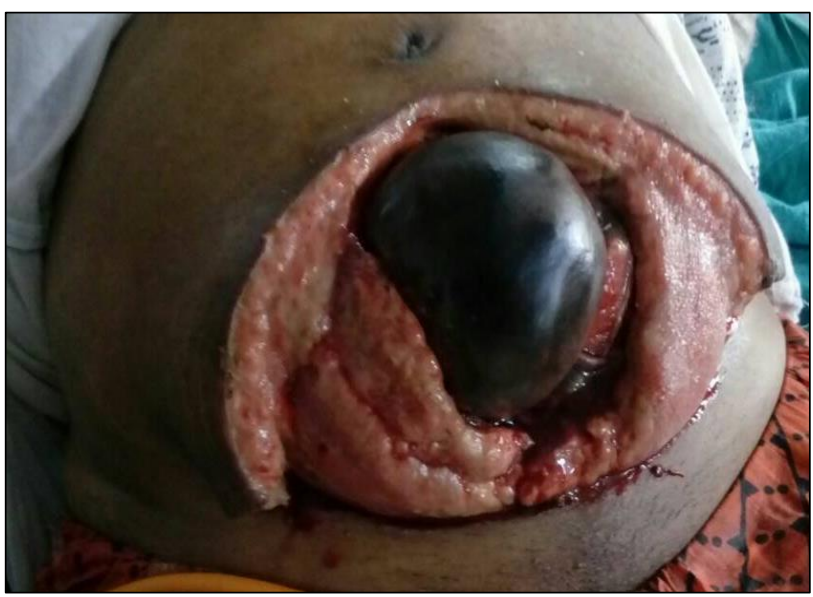

Figure 2: Uterine necrosis with abdominal compartment syndrome.

Abdominal muscles were swollen. As primary closure was difficult due to abdominal compartment syndrome, bogota bag dressing was applied. Patient was shifted to ward and broad-spectrum antibiotics were started. Patient continued to have high grade fever. Gradually on examination, central part of uterus between two parallel compression sutures was necrosed, bluish-black and friable (Figure 2). Purulent and foul-smelling discharge was present. Decision for post-partum hysterectomy was taken. Per operatively, uterus was necrosed in centre between compression suture, remaining uterus and bilateral tubes, ovaries were normal, blood mixed purulent fluid was present between gut loops. Dense adhesions were present between gut loops and posterior surface of uterus. Total abdominal hysterectomy was done. Burst abdomen occurred on $4^{\text {th }}$ post-operative day. Daily antiseptic dressing was done. Wound was allowed to heal by secondary intention. On serial sectioning, uterus was gangrenous and necrotic. No clear-cut identification of endomyometrium could be made out. Microsections showed that endometrial cavity was filled with gangrenous slough extending to variable extent in myometrium and cervix (Figure 3 ).

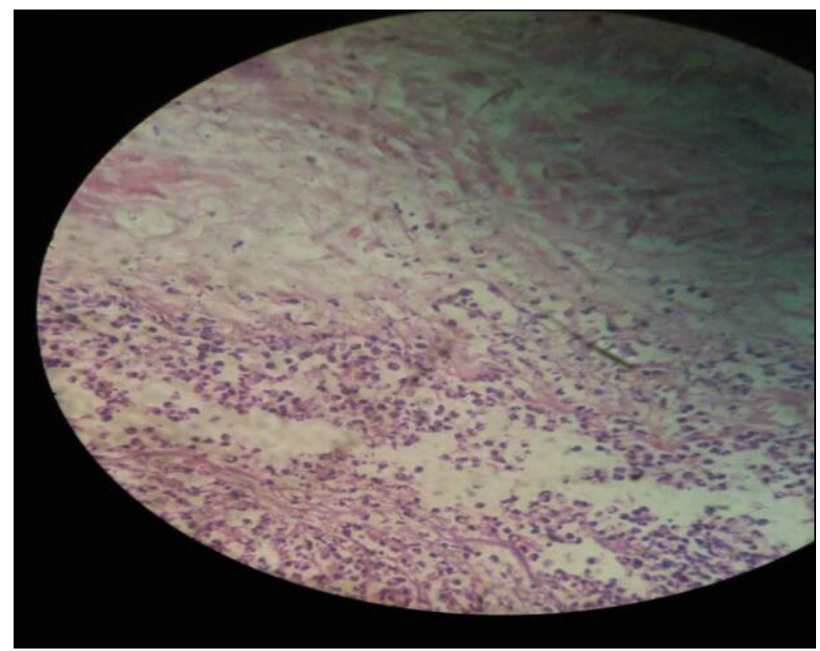

Figure 3: Microsection showing uterine necrosis

\section{DISCUSSION}

Major postpartum haemorrhage is a significant obstetric emergency requiring prompt management. Major postpartum haemorrhage is a significant obstetric emergency requiring prompt management. The cornerstone of management of PPH is a team approach and early diagnosis. Resuscitation, uterotonics, uterine tamponade procedures and selective radiological embolization of the bleeding vessel have all been used successfully. However, the failure of conservative management often mandates surgical intervention. The choice of type of surgical intervention depends on parity and the desire for future children, the extent of the hemorrhage, the general condition of the patient and the experience of surgeon. Ligation of the uterine artery or its main supply (internal iliac artery) require above average surgical skill and may be successful in less than half of cases. $^{5-7}$ Selective arterial embolisation require an interventional radiologist and a hemodynamically stable patient for its successful application. Traditionally if all these fail, definite surgical management by doing obstetric hysterectomy led to permanent sterility causing significant physical and psychological morbidity.

The B-Lynch technique of a 'belt and braces' uterine compression suture was described in 1997 as an alternative to caesarean hysterectomy, pelvic vascular surgery or interventional radiological procedures (such as 
uterine artery embolisation) in the case of major postpartum haemorrhage. ${ }^{4}$ The surgical technique involves the placement of pair of vertical brace sutures around the uterus, essentially to appose the anterior and posterior walls. These compression sutures work by direct application of pressure on placental bed bleeding and by reducing blood supply to uterus.

The success rate of $B$ Lynch suture, in avoiding hysterectomy is $86.4 \%$ and it has been widely recommended for controlling $\mathrm{PPH} .{ }^{4}$ Following recovery from a PPH treated with a uterine compression suture, complications have been reported in various studies including Asherman's syndrome, hematometra, pyometra, localized areas of uterine necrosis and fullthickness defects in the lower uterine segment or uterine fundus and erosion of uterine wall.

$\mathrm{Wu}$ and Yeh reported uterine synechiae formation following square sutures, which were visible at hysteroscopy two years after the procedure. ${ }^{8,9}$ This may have been caused by use of delayed absorbable suture (10 dexon polyglycolic acid suture). Ochoa et al reported development of pyometra following square sutures in a case of chorioamnionitis. ${ }^{10}$ The patient presented 4 weeks postpartum with fever and an enlarged uterus filled with infected lochia. Two other instances of uterine necrosis following B-Lynch sutures have also been reported. Akoury $\mathrm{H}$ and Sherman $\mathrm{C}$ reported a healthy 32-year-old woman, gravida 3, para 0 who underwent Caesarean section at 41 weeks' gestation with one B-Lynch plus two Cho sutures were used to control PPH. During subsequent pregnancy, a large triangular myometrial defect was identified in the mid-anterior uterine wall and two smaller defects in the posterior wall. Operative resection was done for the same. Authors hypothesized that the compressing produced after application sutures caused myometrial necrosis in the uterine musculature. ${ }^{11}$

Treolar EJ et al had suggested that the mechanism of uterine damage after compression sutures might have been due to venous rather than arterial infarction keeping in mind the significantly increased postnatal vascularity of the uterus with extensive anastomotic vessels within the pelvis and as a result uterine necrosis should be rare. So, they proposed that an incorrectly placed B-Lynch suture could have interrupted the uterine arterial blood flow to the myometrium resulting in necrosis. ${ }^{10}$

\section{CONCLUSION}

Various uterine compression sutures have been devised during the last 15 years. Data indicate that these procedures generally achieve good haemostasis without grave complications. The choice may depend on several factors, i.e. bleeding site, bleeding severity, and disorders causing PPH and most importantly the experience of the surgeon. We should try to choose the best suture individually for each patient. Since the best procedure has not yet been determined, and since the chance to employ compression sutures is not very frequent in routine practice, it may be practical at present to become accustomed to one procedure.

\section{Funding: No funding sources \\ Conflict of interest: None declared \\ Ethical approval: Not required}

\section{REFERENCES}

1. Kwast BE. Postpartum hemorrhage: its contribution to maternal mortality. Midwifery. 1991;7:64-70.

2. World Health Organisation. Maternal mortality: a Global Factbook. Geneva, WHO; 1991. Available at http://apps.who.int/iris/bitstream/10665/38317/1/WH O_MCH_MSM_91.3.pdf

3. Khan KS, Wojclyle D, Say L, Gulmazoglu AM, Vanlook PF. WHO analysis of causes of maternal death, a systematic review. Lancet. 2006;267:106674.

4. B-lynch C, Coker A, Lawal AH. The B-lynch surgical technique for the control of massive postpartum hemorrhage: an alternative to hysterectomy? Five cases reported. $\mathrm{Br} \mathrm{J}$ Obstet Gynecol. 1997; 104:372-5.

5. Pahlavan P, Nezhat C. Haemorrhage in obstetrics and gynecology. Curr Opin Obstet Gynecol. 2001;13(4);419-424.

6. Evan S, MeShane P. The efficacy of internal iliac artery ligation in obstetric haemorrhage. Surg Gynecol Obstet. 1985;160;250-3.

7. Roman AS, Rebarber A. Seven ways to control postpartum haemorrhage. Contemp Obstet Gynecol. 2003;98(3):34-53.

8. $\mathrm{Wu} \mathrm{HH}$, Yeh GP. Uterine cavity synechiae after hemostatic square suturing technique. Obstet Gynecol. 2005;105:116-7.

9. Treloar EJ, Anderson RS, Andrews HS, Bailey JL. Uterine necrosis following B-Lynch suture for primary postpartum haemorrhage. $\mathrm{Br} \mathrm{J}$ Obstet Gynecol. 2006;113:486-8.

10. Ochoa M, Allaire AD, Stitely ML. Pyometria after hemostatic square suture technique. Obstet Gynecol 2002;99:506-9.

11. Akoury H, Sherman C. Uterine wall partial thickness necrosis following combined B-Lynch and Cho square sutures for the treatment of primary postpartum hemorrhage. J Obstet Gynaecol Can. 2008;30:421-4.

Cite this article as: Chaudhary $\mathrm{S}$, Singh $\mathrm{P}$, Meenakshi B, Gupta A, Ramola M. Uterine necrosis following B Lynch suture: a rare complication. Int J Reprod Contracept Obstet Gynecol 2018;7:745-7. 